\title{
Recombinant Oncorhyncin II Effect on the Treatment of Methicillin-Resistant Staphylococcus aureus Skin Infection
}

\author{
Seyedeh Fatemeh Jafari (ii) ${ }^{1}$, Ehsanollah Ghaznavi-Rad (iD ${ }^{2}$, Shohreh Fahimirad ${ }^{3}$ and Hamid Abtahi (iD) ${ }^{3,}{ }^{*}$ \\ ${ }^{1}$ Students Research Committee, Faculty of Medicine, Arak University of Medical Sciences, Arak, Iran \\ ${ }^{2}$ Department of Medical Laboratory Sciences, Arak School of Paramedicine, Arak University of Medical Sciences, Arak, Iran \\ ${ }_{3}^{3}$ Molecular and Medical Research Center, Arak University of Medical Sciences, Arak, Iran \\ Corresponding author: Molecular and Medicine Research Center, Arak University of Medical Sciences, Arak, Iran. Tel: +98-8634173502, Fax: +98-8634173526, Email: \\ abtahi@arakmu.ac.ir \\ Received 2019 July 03; Revised 2020 April 17; Accepted 2020 April 28.
}

\begin{abstract}
Background: Methicillin-resistant Staphylococcus aureus (MRSA) is known to be one of the most potentially pathogenic organisms in the world. Skin infections are one of the significant infections of S. aureus. Therefore, therapeutic constraints have challenged researchers to seek new strategies to produce new medicines. Antimicrobial peptides (AMPs) are a new generation of natural drugs with antimicrobial properties and high fatality potency. Oncorhyncin II AMP is a group of peptides with bacteriostatic activity and antimicrobial effect against Gram-positive and Gram-negative bacteria. Therefore, the development and promotion of antimicrobial peptides can be a new step in the treatment of skin infections due to bacterial resistant S. aureus in hospitals.

Objectives: The objective of this study was to produce recombinant Oncorhyncin II protein and evaluate its antimicrobial effects on MRSA to determine the outcomes of the treatment.

Methods: In this experimental study, the Oncorhyncin II Antimicrobial peptide was synthesized by the recombinant method. The effectiveness of this peptide was assessed by the minimum inhibitory concentration (MIC) test. The activity of recombinant protein against S. aureus was investigated using in vitro and in vivo experiments.

Results: The effectiveness of this peptide obtained by the MIC test was $225 \mu \mathrm{g} / \mathrm{mL}$. The activity test confirmed the MIC test and showed that this antimicrobial peptide has been able to reduce MRSA cell growth. All mice infected with MRSA responded positively to the protein treatment.

Conclusions: According to Oncorhyncin II antimicrobial peptide activity studies, this peptide, as a new generation of antibiotics, was expected to have positive outcomes in the improvement of $S$. aureus skin infections. Therefore, the results of the efficacy require further studies to be confirmed.
\end{abstract}

Keywords: Staphylococcus aureus, Oncorhyncin II Antimicrobial Peptide, Molecular Cloning, Recombinant Protein

\section{Background}

According to the estimates made by the Healthcare Centers and Prevention of Infections and Diseases hospitals in the world, thousands of people died every year due to infections caused by drug-resistant bacteria despite the high cost of the treatment $(1,2)$. One of the main concerns that challenged hospitals is the rapid outbreak of resistance to this Pathogen $(3,4)$. According to the world health organization (WHO), one of the most common infectious organisms threatening public health is Staphylococcus au reus bacterium. Staphylococcus aureus is colonized in the nose, skin, and other parts of the body. Skin infections are one of the most important infections of this bacterium, and the rate of infection in hospitals is increasing. Therefore, developing the antibiotic resistance of this bacterium puts serious obstacles in the way of therapeutic processes $(5,6)$.

Nowadays, scientists consider the antimicrobial peptides (AMPs) as a new generation of antibiotics for the future. These peptides have high killing power against pathogenic agents such as bacteria, fungi, parasites, and viruses (7-9). Oncorhyncin II is an AMP secreted from rainbow trout. This peptide, in addition to potential antimicrobial properties, has a lower toxicity than other AMPs. Oncorhyncin II AMP, like other AMPs, has a destructive effect on a wide range of Gram-positive and Gram-negative bacterial membranes. Therefore, the Oncorhyncin II peptide with the collapse of the bacterial membrane leads to the lysis and, ultimately, the death of bacteria $(10,11)$. 


\section{Objectives}

In this study, the recombinant Oncorhyncin II protein was synthesized by the cloning method and its activity, and inhibitory effects on methicillin-resistant Staphylococcus aureus (MRSA) were evaluated using in vitro and in vivo experiments. Moreover, the wound healing process in infected mice with protein was assessed by microscopic images.

\section{Methods}

3.1. Cloning, Expression and Purification of Recombinant Protein Oncorhyncin II

The gene synthesized Oncorhyncin II was purchased from the Biometic, Canada. The Polymerase chain reaction (PCR) product of Oncorhyncin II gene was digested with BamH1 and Xho1 enzymes purchased from Fermantas, Lithuania for cloning in Escherichia coli. Then, pET32a plasmid vector was also digested with the same digestive enzymes (BamH1 and Xho1 restriction enzymes) under similar conditions. Then, to ligate the Oncorhyncin II gene to the pET32a plasmid, cleavage sites were created for the BamH1 and Xho1 restriction enzymes in this gene to construct two sticky ends (12). Lastly, pET32a and digested gene fragment for ligation reaction were placed in the Proximity of T4 DNA ligase (Fermantas, Lithuania) for $1 \mathrm{~h}$ at $22^{\circ} \mathrm{C}$ (13). The E. coli $\mathrm{DH} 5 \alpha$ strain was applied as the primary host for the replication of the recombinant plasmid. The pET32a with recombinant DNA produced by transformation method was transferred to host bacteria E. coli DH5.

PCR and mini-preparation plasmid were applied to confirm bacteria that carried recombinant DNA. The pET32a expression vector and E. coli BL21 (DE3) host expression was utilized to gene expression. Colonies of E. coli BL21 (DE3) were cultured in Nutrient Broth Medium containing ampicillin antibiotic to induce protein expression in the bacterial host. Then, $500 \mu \mathrm{L}$ of cultured bacteria were added to $50 \mathrm{ml}$ of induction medium and shacked at $37^{\circ} \mathrm{C}$ at $140-220 \mathrm{rpm}$ on a shaker incubator. After the bacteria reached to mid-log phase (OD600 $=0.6)$, Isopropyl $\beta$-D-1Thiogalactopyranoside (IPTG) (Fermantas, Lithuania) with a final concentration of $1 \mathrm{mM}$ was added to the bacterial suspension to induce protein expression. Then, $2 \mathrm{~h}$ after the addition of Isopropyl $\beta$-D-1-thiogalactopyranoside (IPTG), $50 \mathrm{~mL}$ of bacterial suspension centrifuged at 4000 rpm for 5 minutes. The induction result was confirmed by transferring the resulting protein to the $(12 \%)$ Sodium dodecyl sulfate-polyacrylamide gel electrophoresis (SDSPAGE) gel. Finally, the extraction of synthesized recombinant protein was performed by using Ni-NTA kit (Qiagen, USA), according to the manufacturer's instructions $(14,15)$.

\subsection{Refolding Optimization of Oncorhycin II}

Employing urea for protein purification denatures the active folding of proteins. The chemicals used in making buffer and other required solutions were prepared from Merck, Germany and enzymes were purchased from Fermantas, Lithuania. Therefore, the purified protein was dialyzed by phosphate-buffered saline (PBS) at different $\mathrm{pH}$ conditions. Urea was utilized to prevent peptide aggregation during the peptide purification step. Accordingly, for recovery of the peptide refolding, elimination of urea by dialysis method was essential. For this purpose, the sample was poured into dialysis bags (10k molecular weight cut-off (MWCO Thermo Scientific), and under different PBS conditions (Table 1), it was placed at $4^{\circ} \mathrm{C}$. After every $2 \mathrm{~h}$, the dialysis buffer was replaced to increase the dialysis efficiency. Finally, the dialyzed protein was stored at $4^{\circ} \mathrm{C}$ for further testing.

\begin{tabular}{lc}
\hline Table 1. Different Dialysis Conditions & \\
\hline Combination of PBS buffer with Arg/Pro/Cys/Gly & $\mathbf{p H}$ \\
\hline PBS & 7 \\
Pro (1M) & 5 \\
\hline $\operatorname{Pro}(\mathbf{1 M})$ & 7 \\
$\operatorname{Cys}(\mathbf{1 M})$ & 5 \\
\hline $\operatorname{Pro}(\mathbf{1 M})+\operatorname{Cys}(\mathbf{1 M})$ & 5.5 \\
\hline $\operatorname{Arg}(\mathbf{1 M})+\mathbf{G l y}(\mathbf{1 M})$ & 6.5 \\
\hline $\operatorname{Pro}(\mathbf{1 M})+\operatorname{Arg}(\mathbf{1 M})$ & 7 \\
\hline $\operatorname{Pro}(\mathbf{1 M})+\operatorname{Arg}(\mathbf{1 M})$ & 8.5 \\
\hline
\end{tabular}

\subsection{Antibacterial Activity Test}

The antibacterial activity assay was performed according to the National Committee for Clinical Laboratory Standards method M7-A7 (16). Antibacterial Activity of Oncorhyncin II protein against MRSA was investigated by the turbidity assay. Oncorhyncin II protein activity was measured by cell lysis monitoring of MRSA cell suspension at OD600 $\mathrm{nm}$. Therefore, bacterial cultures were performed in the Muller-Hinton broth (MHB) at $37^{\circ} \mathrm{C}$ and under gentle shaking $(180 \mathrm{rpm})$ for $18 \mathrm{~h}$. Then, the cells were centrifuged at $5320 \mathrm{rpm}$ for $10 \mathrm{~min}$ and washed twice with PBS. The pellet was suspended in MHB broth and a bacterial suspension was prepared with a turbidity of 0.55 at OD600 $\mathrm{nm}$. Subsequently, $125 \mu \mathrm{g}$ of Oncorhyncin II protein (1.4 $\mathrm{mg} / \mathrm{mL}$ ) was added to glass vials containing $375 \mu \mathrm{L}$ of the bacterial suspension. These glass vials consisted of a sample (suspension containing Oncorhyncin II protein), the negative control sample (protein-free suspension) and the positive control sample (containing $16 \mu \mathrm{L}$ of Ampicillins 
antibiotics), respectively. Suspension turbidity was measured at OD600 nm using a spectrophotometer (17).

\subsection{Antimicrobial Susceptibility Testing}

\subsubsection{Minimum Inhibitory Concentration}

The minimum inhibitory concentration (MIC) of the Oncorhyncin II antimicrobial peptide was measured in 96well microliter plates against MRSA (ATCC 25923) according to the CLSI protocol. Serial dilutions of MRSA (OD600) were carried out in the MHB culture and transferred to the wells. After this step, Oncorhyncin II protein with a concentration of $1800 \mu \mathrm{g} / \mathrm{mL}$ into the wells. Next, the plate was incubated at $37^{\circ} \mathrm{C}$ for $24 \mathrm{~h}$. After the incubation, reassuring dyes were added to the wells and the results were read (18).

\subsubsection{Evaluation of Antimicrobial Effect In Vivo}

The mice used in this study were mature males from Westar mice. In the method of local infection, mice were divided into three groups as follows: the negative control (Group without treatment), positive control (2\% Mupirocin ointment treatment), and treatment with Oncorhyncin II recombinant protein. In this method, the mice (200 and $250 \mathrm{~g}$ ) were kept in a light-dark cycle for 12 $\mathrm{h}$ at $22^{\circ} \mathrm{C}$ for the adaptation to the condition. Initially, the mice were anesthetized by Ketamine and then the posterior part of the neck of the mice was shaved. The space of the shaved region was $22 \mathrm{~cm}$ infected with MRSA (1.5 $\times 108 \mathrm{CFU}$ ). Two days after infecting the mice, the sample was taken from the contaminated area. After infecting the tissue, the treatment was performed using 1000 $\mu \mathrm{g} / \mathrm{mL}$ recombinant protein (recombinant Oncorhyncin II in Eucerin). The recombinant Oncorhyncin II ointment was scrubbed into a skin scar of mice equally for one week (14 times with a $12 \mathrm{~h}$-interval) and after inoculation, animal skin scar was examined in all three groups.

\subsection{Microscopic Analysis}

After the17th day of the treatment, the complete area of the wound, including the excised area adjacent to normal skin, was removed from the positive and negative groups and blank. The excised tissues were fixed in formalin $(\mathrm{pH}=$ 6.9) and embedded in paraffin. Sectioning was performed, according to stereological methods. In this study, $15 \times 2$ (6 $\mu \mathrm{m}$ thickness) sections were obtained from the healing wounds of each mouse. The sections were stained with hematoxylin and eosin ( $\mathrm{H} \& \mathrm{E}$ ), observed, and evaluated by stereological methods. Hereby, 1,050 random fields of all specimens of each group $(n=7)(8,400$ microscopic fields, totally $7.43 \mathrm{~mm}^{2}$ for all groups) were photographed, and a $10 \times 100$ objective lens (NIKON-Eclipse E2000-Videocamera DS-Fi1, Japan) was applied.

\section{Results}

\subsection{Amplification of Oncorhyncin II by PCR}

Following the PCR amplification, the products were studied on the agarose gel (Figure 1).

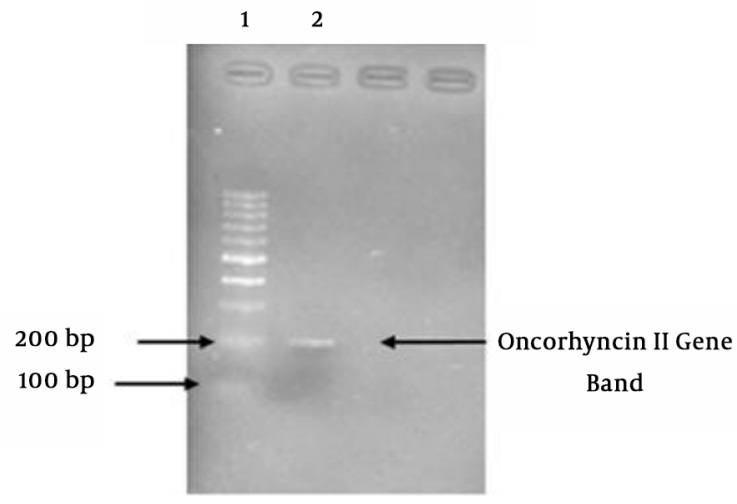

Figure 1. Lane 1: marker, Lane 2: Oncorhyncin II band. As seen the 1000 bp

\subsection{Expression and Purification Oncorhyncin II}

The induction of protein expression in E. coli BL21(DE3) strain was performed using IPTG. Protein was expressed and produced with a molecular weight of $27 \mathrm{kDa}$. Finally, the purification of the protein was verified by SDS electrophoresis (Figure 2).

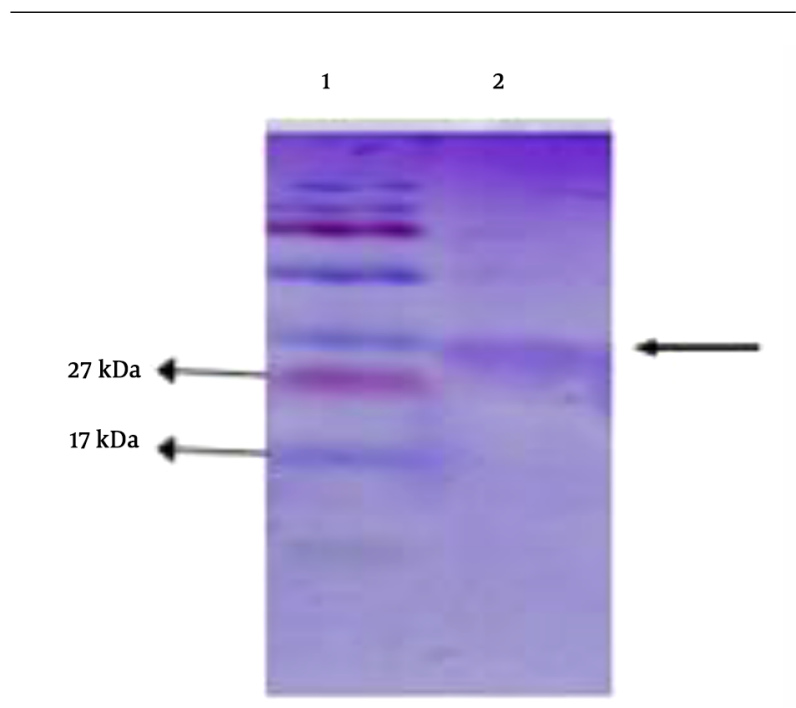

Figure 2. Oncorhyncin II protein purification: Lane 1: protein marker. Lane 2: Oncorhyncin II 


\subsection{Refolding Assessment of Oncorhycin II}

The dialysis method with PBS was done (Table 1). High antibacterial activity of recombinant Oncorhyncin II was attributed to the arginine and proline amino acids at $\mathrm{pH}=$ 8.5. The concentration of Oncorhyncin II protein was measured with the spectrophotometer (Eppendorf, Germany) at OD280 nm. Finally, MIC was utilized to evaluate the effectiveness of Oncorhyncin II on S. aureus MRSA (ATCC25923) using in vitro condition.

4.4. Antibacterial Activity Assay or Growth Curve of Oncorhyncin II Peptide

The growth curves of MRSA treated with Oncorhyncin II are shown in Figure 3 by measuring Optical Density at OD600 nm., the growth curves of E. coli included three phases: lag phase, exponential phase, and stabilization phase. However, decline phases in each growth curve could not be revealed because we only assayed the total numbers of the bacteria, based on the value of OD600. In the absence of Vancomycin and Oncorhyncin II, MRSA reached exponential phase rapidly. The antimicrobial peptide and Vancomycin could reduce MRSA cells' growth at 1, 2 and 4 h. But exposed Vancomycin of MRSA cells were lagged to 7 and $9 \mathrm{~h}$. So with increasing time, peptide activity was reduced, and the MRSA cells' growth curves returned to the enrichment phase (Chart1).

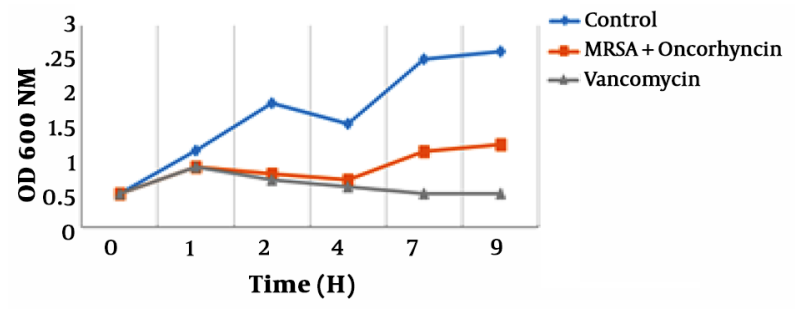

Figure 3. The results of antibacterial activity the recombinant Oncorhyncin II

\subsection{Antimicrobial Susceptibility Testing}

\subsubsection{Minimum Inhibitory Concentration}

The results of this study showed that the MIC for recombinant Oncorhyncin II protein was $225 \mu \mathrm{g} / \mathrm{mL}$ on MRSA (ATCC 25923).

\subsubsection{Antimicrobial Effect of Oncorhyncin II in Mice Models}

The results of the treatment of mice infected with local infection by the MRSA (ATCC 25923) showed that all infected mice were completely treated with the protein. However, no improvement was seen in the mice in the negative control group. As previously mentioned, it was shown that the treatment of the mice with the Oncorhyncin II protein (at a concentration of $1000 \mu \mathrm{g}$ in each mice) resulted in a remarkable improvement in the wound in the treated-protein-mice group compared with the positive and negative groups (Figure 4).

\subsection{Microscopic Analysis}

According to the microscopic images shown in Figure 5 , there is a significant difference in the wound healing of the experimental group post-treatment on day 15 in comparison to the pre-treatment. As shown in A, the wound healing process has been very well-developed due to the presence of small scars in the wound area. B, which is related to the pre-treatment of the experimental group, there is a vast scar area (arrows).

\section{Discussion}

Oncorhyncin II antimicrobial peptide is a fragment of 69 amino acids with a molecular weight of $7.2 \mathrm{kDa}$, derived from the c-terminal region of histone H1produce in the skin of the Rainbow trout fish. In addition to antimicrobial activity on Gram-positive bacteria such as MRSA, Oncorhyncin II has also antimicrobial properties against Gram-negative bacteria such as E. coli. Oncorhyncin II antimicrobial peptide penetrates to bacterial cells through the binding to the teichoic acids bacterial wall and interferes with wall integrity and by interrupting wall integrity, which leads to intracellular material leakage and thereby causing bacterial lysis and its death.

In this study, the Oncorhyncin II gene was amplified by PCR technique and ligated to pET32a vector by BamH1 and Xho1 as restriction enzyme. Given that the pET32a vector is one of the most powerful carriers in the production of soluble proteins, it has broad efficiency to express recombinant proteins in cloning. The plasmid pET32a was then transferred to E. coli BL21 DE3 to express the Oncorhyncin II gene. The pET32a plasmid then transmitted to the E. coli BL21 DE3 gene for expression of Oncorhyncin II gene, it should be noted that this strain does not have known cytoplasmic proteases. Therefore, high protein expression is due to protease deficiency in this strain. The advantages of applying E. coli strain in this study were relatively small genomes and high amplification of Oncorhyncin II gene.

Oncorhyncin II was successfully expressed and confirmed by SDS-PAGE, next, the expressed protein was purified using Ni-NTA kit. The results of the present study showed that the antimicrobial peptide of Oncorhyncin II was expressed at the high amounts by the recombinant method, while in a research conducted by George in 2003, this peptide was expressed and produced in relatively low 

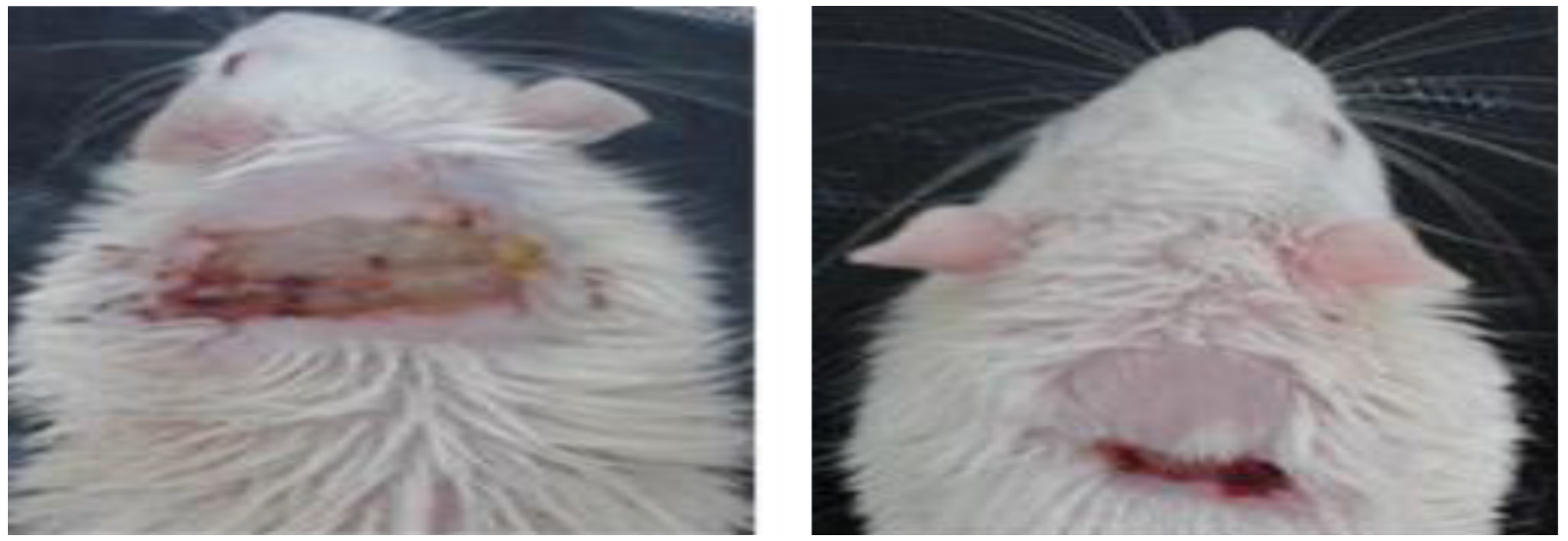

Figure 4. A: topical infected model with MRSA strain (ATCC 25923), B: infected model treated with Oncorhyncin II
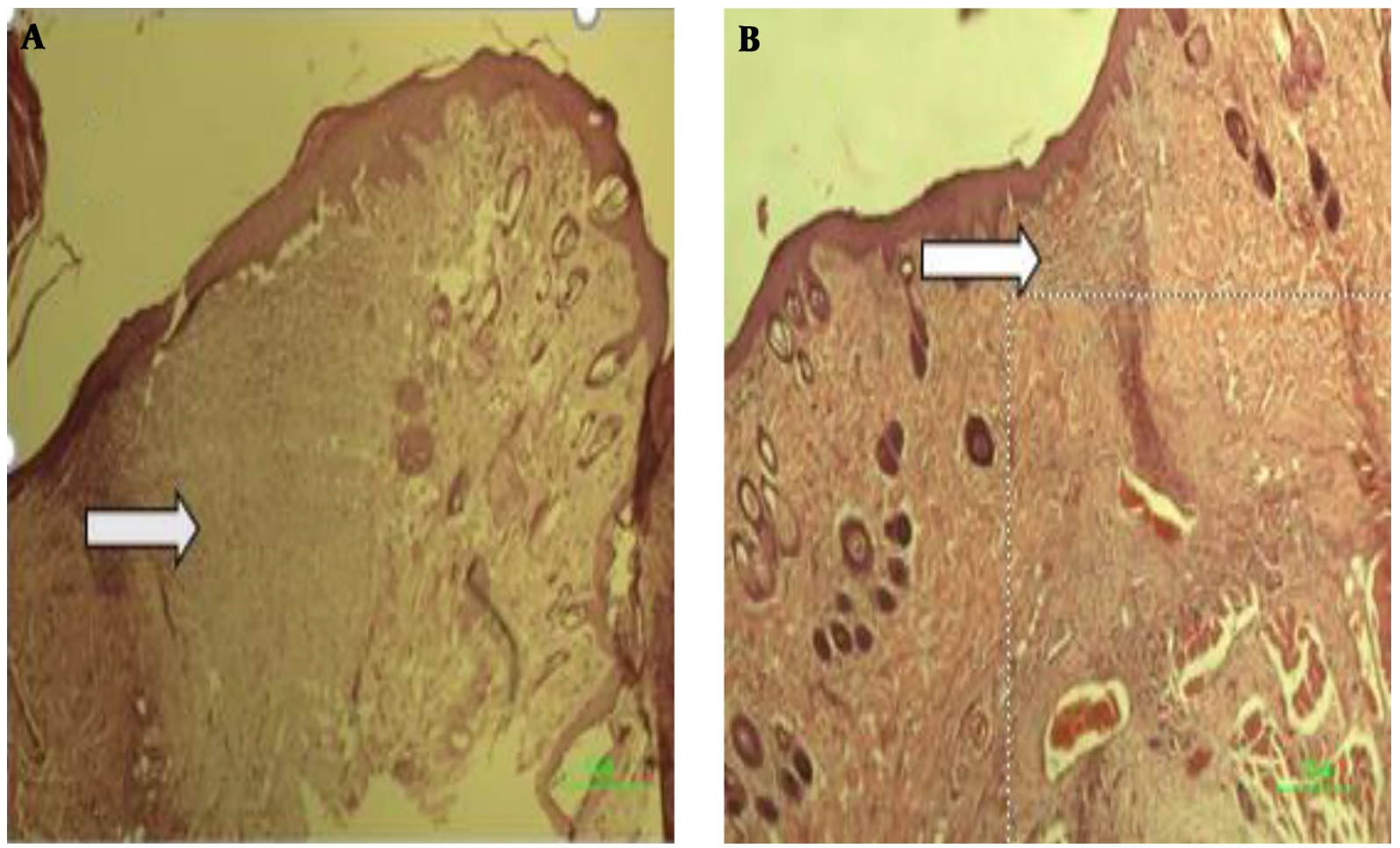

Figure 5. The microscopic photographs of wound areas and adjacent normal skin pre- and post-treatment on the 15th day: In A after the treatment with peptide, the edges of the wound are closed together, indicating a positive effect on the treatment

amounts (11). Therefore, the production of this peptide by the recombinant method, in terms of the economically and production time was more cost-effective. On the other hand, the production of this protein by the recombinant method has also problems such as a sharp decrease in the activity of these proteins due to the loss of its natural structure during its production and purification. Therefore, to overcome this problem, it is necessary to refold the protein structure after the purification step.

Therefore, by utilizing the dialysis method and eliminating factors such as urea, it is feasible to refold the structure of the protein and thereby increasing its function. For this purpose, dialyzed compounds should provide the proper conditions for the formation of correct intramolec- 
ular bonds. Therefore, in this study, the produced and purified Oncorhyncin II protein with various compounds was dialyzed, and the conditions in which the protein had the highest bactericidal property was selected. In this study, PBS with $\mathrm{pH}=8.5$ was the main basis of dialysis buffer. Therefore, various amino acids were employed to create appropriate refolding conditions. Dialysis in the presence of Proline (Pro) in combination with Arginine (Arg) provided the highest antimicrobial effect for the Oncorhyncin II. Therefore, Pro, by binding to the hydrophobic surface of Oncorhyncin II, causes stability and prevents aggregation and ultimately facilitates its refolding. Additionally, Arg interacts with the hydrophilic surface of the peptide and has an inhibitory effect on the formation of inclusion bodies, thereby preventing its accumulation.

The remarkable point is that the refolding of the Oncorhyncin II AMP has a direct correlation with its isoelectric point. The natural isoelectric point of the Oncorhyncin II is 10.5. Therefore, the presence of Pro and Arg amino acids makes the protein able to refold accurately in $\mathrm{pH}=$ 8.5 (19). In the following, MIC test and peptide activity assay were performed for evaluation of the antimicrobial activity of purified peptide against MRSA. In this study, the MIC required for inhibition of MRSA was reported to be $225 \mu \mathrm{g} / \mathrm{mL}$, indicating the functional level and the killing power of this peptide. But in the study of Jacobsen et al., it was observed that MIC of histone $\mathrm{H} 1$ antimicrobial peptides against MRSA was $2,500 \mu \mathrm{g} / \mathrm{ml}(20)$. According to the results of the current study and a study conducted in 2003 by George on Oncorhyncin II AMP, it seems that Oncorhyncin II peptide, like other recombinant AMPs, has high antimicrobial properties to the Annihilation of MRSA. We have demonstrated that Oncorhyncin II has good in vitro activity against infections caused by MRSA.

Based on the results of the protein activity assay, we conclude that the antibacterial effect of the Oncorhyncin II peptide is similar to the Vancomycin so that after $1 \mathrm{~h}$, it can cause a sharp decline in the number of bacteria. Therefore, one of the advantages of this peptide is identical antimicrobial activity similar to Vancomycin against desired bacteria. However, the study on the recombinant porcine beta defensin 2 (pBD2) by Li et al. (2013) on MRSA showed that the maximum effect of this peptide in the activity test was $4 \mathrm{~h}$, and after $4 \mathrm{~h}$ (by increasing the time), the number of bacteria and their growth increased. Therefore, the antimicrobial peptide of Oncorhyncin II has high killing power (21).

Following the confirmation of in vitro experiments, we started in vivo experiments and evaluated the effects of the recombinant peptide of Oncorhyncin II in experimental mice in different therapeutic and non-therapeutic groups. The results of this study showed that skin infections in all mice of the treatment group were treated after receiving Oncorhyncin II AMP, and their wounds well improved and, no effect of MRSA infection was observed. Although wound healing of the rat groups without treatment with the peptide took a long time, the healing process during the treatment period was clearly observed in the treatment group after the first treatment dose.

A study of MRSA skin infections in 2014 showed that the $\mathrm{HH} 2$ antimicrobial peptide had a less therapeutic effect on MRSA infections (22). Therefore, this study showed that the antimicrobial peptide Oncorhyncin II is capable of treating skin infections caused by MRSA. Thus antimicrobial peptide Oncorhyncin II has a high ability to repair the wound caused by this bacterium. In vivo data established that Oncorhyncin II, in comparison to the clinically tested antibiotics, is much more effective against MRSA. Consequently, the Oncorhyncin II peptide as a new drug can be utilized in the treatment of skin infections caused by MRSA bacteria in the future. However, further studies are necessary in this field to confirm the findings.

\subsection{Conclusions}

In this study, for the first time the Oncorhyncin II gene was expressed through cloning in E. coli host and, various tests were performed to evaluate its efficacy using in vitro and in vivo experiments. The MIC and peptide activity assays revealed that peptide has an efficient and powerful antibacterial property against MRSA. On the other hand, pathological studies confirmed that Oncorhyncin II recombinant peptide has potential wound healing effects on this infection since it overcame the MRSA during the treatment, and the wound edge was closed together and improved. Therefore, it seems that this peptide needs further clinical trials to be possibly employed as new generation antibiotics for the treatment of skin infections in hospitals.

\section{Footnotes}

Authors' Contribution: Hamid Abtahi, Ehsanollah Ghaznavi-Rad and Shohreh Fahimirad designed the study, interpretation of the data, and manuscript writing. Seyedeh Fatemeh Jafari performed the experimental studies.

Conflict of Interests: The authors declared no conflict of interest.

Ethical Approval: This research was approved by the Ethics Committee of Arak University of Medical Sciences (ethics code: IR.ARAKMU.REC.1396.173). 
Funding/Support: This work was funded by the grant number of 2854 obtained from Arak University of Medical Sciences.

\section{References}

1. Sun L, Chen Y, Wang D, Wang H, Wu D, Shi K, et al. Surgical site infections caused by highly virulent methicillin-resistant Staphylococcus aureus sequence type 398, China. Emerg Infect Dis. 2019;25(1):157. doi: 10.3201/eid2501.171862. [PubMed: 30561317]. [PubMed Central: PMC6302609].

2. Nead JA. Bacterial Infections of the Skin and Skin Structures. Introduction to Clinical Infectious Diseases. Springer; 2019. p. 3-15.

3. Hitchman LH, Smith GE, Chetter IC. Prosthetic infections and high-risk surgical populations. Surgery. 2019;37(1):38-44. doi: 10.1016/j.mpsur.2018.11.004.

4. Ho PL, Ong HK, Teo J, Ow DS, Chao S. HEXIM1 peptide exhibits antimicrobial activity against antibiotic resistant bacteria through guidance of cell penetrating peptide. Front Microbiol. 2019;10:1-10. doi: 10.3389/fmicb.2019.00203.

5. Kesharwani AK, Mishra J. Detection of $\beta$-lactamase and antibiotic susceptibility of Clinical Isolates of Staphylococcus aureus. Biocatal Agric Biotechnol. 2019;17:720-5. doi:10.1016/j.bcab.2018.12.012.

6. Turner NA, Sharma-Kuinkel BK, Maskarinec SA, Eichenberger EM, Shah PP, Carugati M, et al. Methicillin-resistant Staphylococcus aureus: an overview of basic and clinical research. Nat Rev Microbiol. 2019;17:20318. doi: 10.1038/s41579-018-0147-4.

7. Jin G, Weinberg A. Human antimicrobial peptides and cancer. Semin Cell Dev Biol. 2019;88:156-62. doi: 10.1016/j.semcdb.2018.04.006. [PubMed: 29694838].

8. Yazici H, Habib G, Boone K, Urgen M, Utku FS, Tamerler C. Selfassembling antimicrobial peptides on nanotubular titanium surfaces coated with calcium phosphate for local therapy. Mater Sci Eng C Mater Biol Appl. 2019;94:333-43. doi: 10.1016/j.msec.2018.09.030.

9. Ciumac D, Gong H, Hu X, Lu JR. Membrane targeting cationic antimicrobial peptides. J Colloid Interface Sci. 2019;537:163-85. doi: 10.1016/j.jcis.2018.10.103.

10. Choi J, Lyons DB, Kim Y, Moore JD, Zilberman D. DNA methylation and histone $\mathrm{H} 1$ cooperatively repress transposable elements and aberrant intragenic transcripts. bioRxivorg. 2019. doi:10.1101/527523.

11. Fernandes JM, Molle G, Kemp GD, Smith VJ. Isolation and characterisation of oncorhyncin II, a histone H1-derived antimicrobial peptide from skin secretions of rainbow trout, Oncorhynchus mykiss. Dev Comp Immunol. 2004;28(2):127-38. doi: 10.1016/S0145-305X(03)001204

12. Mirjamali NA, Soufian S, Molaee N, Abbasian SS, Abtahi H.Cloning and expression of the enzymatic region of Streptococcal hyaluronidase. Iran J Basic Med Sci. 2014;17(9):667-72. [PubMed Central: PMC4322150].

13. Molaee N, Abtahi H, Mosayebi G. Expression of recombinant streptokinase from streptococcus pyogenes and its reaction with infected human and murine sera. Iran J Basic Med Sci. 2013;16(9):985-9. [PubMed Central: PMC3804847].

14. Farjadi V, Abtahi H, Zolfaghari MR, Soufian S, Hasanzadeh L. Expression, purification and evaluation of antigenicity of caga antigenic fragment of helicobacter pylori. Jundishapur J Microbiol. 2013;6(9). 7367. doi: $10.5812 / j j m .7367$

15. Hamzehloo Z, Mosayebi G, Khansarinejad B, Zolfaghari M, Abtahi $H$. Antigenicity Identification of a Novel Recombinant Multi-Epitope Antigen Based on FlaA and UreB Antigens of Helicobacter pylori. Jundishapur J Microbiol. 2019;12(5):1-7. doi: 10.5812/jjm.66502.

16. Wikler MA. Methods for dilution antimicrobial susceptibility tests for bacteria that grow aerobically: approved standard. CLSI (NCCLS). 2006;26(2):M7-A7. Pennsylvania: Clinical and Laboratory Standards Institute.

17. Satishkumar R, Sankar S, Yurko Y, Lincourt A, Shipp J, Heniford BT, et al. Evaluation of the antimicrobial activity of lysostaphin-coated hernia repair meshes. Antimicrob Agents Chemother. 2011;55(9):437985. doi: 10.1128/AAC.01056-10.

18. Waitz JA. Methods for dilution antimicrobial susceptibility tests for bacteria that grow aerobically. 2 nd ed. Villanova, Pa: National Committee for Clinical Laboratory Standards; 1990.

19. Sadoogh Abbasian S, Soufian S, Ghaznavi-Rad E, Abtahi H. High Level Activity of Recombinant Lysostaphin After Computer Simulation and Additive-Based Refolding. Int J Pept Res Ther. 2018;25:1241-9. doi: 10.1007/s10989-018-9769-7.

20. Jacobsen F, Baraniskin A, Mertens J, Mittler D, Mohammadi-Tabrisi A, Schubert S, et al. Activity of histone H1. 2 in infected burn wounds. J Antimicrob Chemother. 2005;55(5):735-41. doi:10.1093/jac/dki067.

21. Li C, Xu T, Chen R, Huang X, Zhao Y, Bao Y, et al. Cloning, expression and characterization of antimicrobial porcine $\beta$ defensin 1 in Escherichia coli. Protein Expr Purif. 2013;88(1):47-53. doi: 10.1016/j.pep.2012.11.015.

22. Wu X, Wang Z, Li X, Fan Y, He G, Wan Y, et al. In vitro and in vivo activities of antimicrobial peptides developed using an amino acid-based activity prediction method. Antimicrob Agents Chemother. 2014;58(9):5342-9. doi: 10.1128/AAC.02823-14. [PubMed: 24982064]. 